\title{
Critical Incidents and Librarian Professional Identity in LIS Pedagogy: Research Methodology as Pedagogical Tool Embedded in Reflexive Practice
}

\author{
Cameron M. Pierson, Anne Goulding, Jennifer Campbell-Meier \\ Victoria University of Wellington, New Zealand \\ piersoca@gmail.com, anne.goulding@vuw.ac.nz,jennifer.campbell-meier@vuw.ac.nz
}

\begin{abstract}
Traditional conceptualisations of the library profession have been challenged due to persistent societal change, similarly affecting professional education. Challenges resulting from such change can be understood as uncertainty of definition and fit in society, and thus a questioning of professional identity. Examinations of professional identity offers potential in practice when introduced in the educational context. This paper outlines a pedagogical tool adapted from a method used in research investigating public librarian professional identity in New Zealand. The tool leverages the elicitation of critical incidents, along with guided questions, to prompt examination of professional identity. The tool is embedded within reflexive practice, creating a framework to understand and engage within increasingly interconnected and changing contexts.
\end{abstract}

\section{ACKNOWLEDGMENTS}

The author would like to thank Dr. J. L. Pecoskie for use and adaptation of assignment format as the basis for the pedagogical tool iteration outlined in this paper.

\section{ALISE RESEARCH TAXONOMY TOPICS}

education programs/schools; pedagogy; research methods; students

\section{AUTHOR KEYWORDS}

critical incidents; professional identity; reflexivity; reflexive practice; librarians; library and information science education 


\section{INTRODUCTION}

In the face of persistent societal changes, traditional conceptualisations of the library profession have been challenged. While previous discussions of the so-called crisis have had various foci (e.g., Bak, 2002; Bennett, 1988; Harris, 1992), these dynamics outline a profession in transition. This professional transition underscores questions of definition and fit of the library and the librarian in modern society. At their core, these are questions of professional identity of practitioners in a social institution characterised by a co-constructed relationship. Professional identity is the product of the impact professional and/or organisational life has had on one's perception of their identity within its context (Whyte, 1956/2002), influencing behaviour and discourse (Sundin \& Hedman, 2009). Professional identity, therefore, plays a key role within coconstructed relationships, which characterises the modern practice of librarianship.

The library profession's education is similarly affected as it also sits within the context of persistent change and institutional structures (Drabinski, 2016). For many entrants, professional identity development begins in professional education. This early developmental phase presents the first opportunity for many entrants to initialise an understanding of librarian professional identity and begin embedding it within self-perception (Pierson et al., 2019). Formal education provides opportunities for profession-specific socialisation and initial conceptualisation of individual relationship to the broader profession (Pierson et al., 2019).

For example, differences among educational institutions may have an impact on identity construction, such as through programme emphases and offerings (Hussey \& Campbell-Meier, 2016). It also has been suggested that content is a stronger influence than medium of instruction as related to professional identity construction (i.e., online and/or in-person) (Hussey \& Campbell-Meier, 2016, p. 354). This would further suggest first, that the nature of social interaction is a key contributor to any associated dynamic regardless of instructional model, and second, that core courses help develop shared values within the profession and a practitioner's individual identity understanding.

Examination of professional identity offers potential for long-term benefit for practitioner and profession in an increasingly interconnected information and professional world. Its examination in the educational environment is advantageous in the professional identity developmental process and adaptable to local context. This paper builds on previous discussions on broad opportunities of examining professional identity in library and information science (LIS) education (Pierson et al., 2020b).

\section{OBJECTIVES}

The objectives of this paper are:

1. Outline how methodology used in a research context can be adapted as a pedagogical tool to prompt professional identity reflection to develop awareness into future practice.

2. Embed the pedagogical tool within reflexive practice as an effective framework to understand and engage with persistent change.

\section{STUDY CONTEXT}


The proposed pedagogical tool is derived from a doctoral research project examining the professional identity of public librarians in New Zealand. Adopting a mixed-methods approach, Phase 1 used a questionnaire to operationalise aspect of a developmental model of librarian professional identity (Pierson et al., 2019). Phase 2 consisted of in-depth follow-up interviews with participants purposefully chosen based on responses to open-ended questions, including critical incidents, in the questionnaire (Pierson et al., 2020a).

Critical incident exploration was a key aspect of the overall research project, highlighting behaviour and its effects (Flanagan, 1954), as relating to librarianship. Among the open-ended questions in the questionnaire, respondents were asked the following:

1. Think of an important event or events that has/have impacted your identity as a librarian. Please describe the event(s).

2. Please elaborate on what specifically made the event(s) impactful to your identity as a librarian.

Follow-up interviews involved discussion on the incidents provided in the questionnaire. After respondents had elaborated on the incident(s), they were asked to confirm the overall sentiment of the incident, whether positive, negative, or including aspects of both. Following this, respondents were prompted for another critical incident with a sentiment opposite to the one provided in the questionnaire. If sentiment included aspects of both, the additional critical incident was prompted in a general way.

Each discussion around critical incidents in interviews was accompanied by three questions:

1. Why do you think this was the incident(s) you thought of?

2. How do you think it influenced your professional identity?

3. Why do you think it influenced you the way it did?

These questions prompted reflection on the subsequent influences of critical incident(s) on professional identity. They further prompted reflection on how examinations of these questions play a role in perceptions of the profession and undertaking library practice as related to incidents and professional identity. These questions can be understood to represent identity examinations and negotiations, whose nature is to explicitly examine a visceral process (Pierson et al., 2020b). Thus, those engaging with these questions may benefit from prolonged exposure to them (Pierson et al., 2020b).

\section{PEDOGOGICAL TOOL}

The following is a discussion outlining an example adaptation of the proposed pedagogical tool, suited to the nature of the questions being posed. It is important to note this is one interpretation of the form of the tool itself, which is suggested to be adaptable to local contexts and needs. The tool takes the form of a term-long assignment within the graduate education context. It is designed around three central topics for student self-exploration: critical incident(s), librarian professional identity, and reflexivity. The structure of the assignment includes three principle parts. See the appendix for the assignment outline.

\section{Part 1: Reading \& planning segment}


Students are first tasked with creating a schedule or plan indicating when each part of the overall assignment and its associated submissions will be addressed. Students will outline the action-items associated with each part (suggested naming is provided) and they must determine when each segment is to be completed. If there is a deliverable, the date they indicate is the date it must be submitted to the instructor. The ethos adopted by this tool emphasises a studentcentred approach. It provides students with the ability to take control and ownership of this assignment from the beginning. It mirrors professional practice in creating a need for and promoting self-directed planning, schedule making, and time management. Additionally, it applies these developed skills and competencies in an authentic way to the students' lives, which may include full- or part-time work, study, or other demands on time. Finally, it offers potential to be complimented within any module or unit addressing professional development, which in many professional, national, and cultural contexts is self-directed, and thus involves an element of initiative

The first deliverable is this plan, outlining action-items and due dates. This segment also outlines the required readings scaffolding the entire assignment. The first reading reviews relevant literature on librarian professional identity and outlines the process of this identity development (Pierson et al., 2019). The second reading offers a general introduction to reflexivity (Archer, 2013), while the third reading situates reflexivity within professional identity development in the higher education context (Ryan \& Carmichael, 2016). These readings offer a foundational introduction to the core concepts of the assignment, each with a distinct advantage: the first presents an overview of previous research and a developmental model focused on process, not an essentialist presentation of identity to which entrants should aspire; the second allows for introduction to reflexivity in a general way, allowing students to contemplate on it before applying it; and the third allows students to examine how professional identity and reflexivity are linked without undue leading though use of literature on a cognate profession. Use of the third paper therefore avoids potential mimicking of content in what is a tool tailored to be personalised to the student.

\section{Part 2: Critical incident exploration}

If already in practice, the students are next asked to reflect on a critical incident in their professional life they consider having impacted their professional identity. If students have not yet been in practice, they are asked to reflect on a critical incident in their life involving a library/archive/information institution they consider as influential and might be brought into their professional identity.

Submission part 2A will ask them to specifically consider the following questions and communicate responses in 250-500 words collectively, with emphasis on description:

1. Think of an important event or events that has/have impacted your identity as a librarian/archivist/information professional, library user/archives user/information professions user. Please describe the event(s).

2. Please elaborate on what specifically made the event(s) impactful to your identity as a librarian/archivist/information professional, library user/archives user/information professions user. 
Submission part 2B asks students to reflexively engage with the critical incident(s) and associated meaning they have described. The emphasis here is on analysis. Specifically, they will consider the following questions in 800-1000 words collectively:

1. Why do you think this was the incident(s) you thought of?

2. How do you think it influenced your professional identity?

3. Why do you think it influenced you the way it did?

\section{Part 3: Final reflexive essay}

The final part of this assignment is a short, 1000-1500 word essay, bringing all parts of the assignment together through the central question: "What does it all mean for your professional identity in professional practice?" Students are asked to analyse the incident(s), focusing on what was learned from the three reflexive questions, and consider any benefits, detriments, and impacts to professional identity, practice, and overall development within an LIS capacity and associated sectors..

The emphasis in this essay is on analytical writing situated in research. At minimum, this is intended to mean drawing on the required readings within this assignment. Students are, however encouraged to draw on other readings in and outside of the given course. To support this specific aspect of the assignment beyond readings already mentioned, a supplemental reading list is provided (Angelides, 2010; Flanagan, 1954; Hicks, 2014; May \& Perry, 2012; McKinney \& Sen, 2012; Pierson et al., 2020a; Sundin \& Hedman, 2009).

\section{Bracketing}

Throughout the assignment, students are provided with sufficient information to understand what is being asked of them and the parameters they can expect to operate in without undue burden. For example, definitions of critical incident(s), guiding questions, and specific reassurances. The required readings provide in-depth discussions from LIS and related literate to develop an understanding of the core topics of exploration. Questions interspersed through the assignment outline support critical engagement with each part of the assignment, providing students with some form of direction balanced with individual latitude. Finally, in its proposed form, the tool offers written reassurance that:

- They are encouraged to share only what they deem relevant and are comfortable with sharing;

- Only the instructor will see and read what is shared.

- This is not psychological assessment, but it is engaging with reflexive practice in an individually meaningful way as it applies to LIS and associated contexts.

- Assessment will not be on the content of any incidents, rather the quality of engagement with the prompts and in communication through the written assignments.

\section{REFLEXIVE PRACTICE}


The proposed pedagogical tool thus introduces entrants to reflexive practice in an authentic way (e.g., Myers, 2010). Its proposed design brackets the tool with an introduction to reflexive practice and its relation to professional identity. Reflexivity indicates a 'bending back' on one's perception in reflecting on a topic (Archer, 2013). Reflexivity is often framed around the metaphor of the driver as the knower, the road as the known, and the windshield as the way to know (May \& Perry, 2012).

Archer (2013) offers a discussion on the "fuzzy" boundaries of reflexive and reflective practice, indicating further adaptability. Indeed, reflexivity can be understood to extend reflective practice, thus offering the ability to include discussions of reflective practice within the present tool or associated module or unit. Reflexive practice, however, moves beyond reflective practice in order to prompt consideration on ways of knowing, influences on those ways, and how those ways influence interactions within practice. This consideration is continuous, iterative, and alongside others (e.g., practitioners and patrons) whose ways of knowing may differ in a constantly changing environment.

Reflexive practice, therefore, is underpinned by identity. The understandings derived from the 'bending back' on an individual's way of knowing are a type of self-analysis which develop professional identity, whose outcomes are embedded into subsequent professional actions and identity perceptions (Ryan \& Carmichael, 2016).

\section{DISCUSSION}

The proposed tool offers a number of distinct benefits. Regarding format, it mirrors practice by creating a need to develop time management skills. The tool's incremental design allows for critical engagement to be developed over time with the introduction of new concepts and aspects to consider, whether from the student or from literature. This aspect allows students to benefit from prolonged exposure to reflexive analysis and the questions provided, as it is suggested such prolonged exposure may be necessary (Pierson et al., 2020b). The tool as proposed is one iteration, and can be adapted to a different assignment format or local need. Moreover, it can complement other, related content, such as continued professional development. The adaptability of the tool is beneficial to educational contexts whose curriculum faces changes in response to changing professional practice contexts and programmes that may not be able to offer time to this topic beyond a sub-unit or self-directed assignment.

Criteria of assessment, however, have been omitted from the present discussion in the interest of adaptability to local contexts and curricula. Additionally, it is self-directed, making it thematically cogent for self-reflexive examination over a period of time. Self-direction within the assignment is a key feature. A purpose of this assignment is situating individual experience and reflexivity as they relate to the students' current and/or future professional practice. Professional identity includes highly personalised aspects (Pierson et al., 2019). Reflexivity and reflexive practice include examinations of individual ways of knowing, not only continuously, but with reference to others' ways of knowing (Pierson et al., 2020b), in constant contexts of change. As such, this pedagogical tool is student-centred and underpinned by a student-led approach. 
The nature of the final submission creates a mechanism for students to combine all of the elements of this assignment in a critical, reflexive way, placing their analysis and themselves within the literature. This supports development of reflexive analysis, and thus reflexivity in practice. What is key to understand is that the proposed pedagogical tool is linked to entrants' future practice in a profession characterised by persistent change and co-constructed relationships. Reflexive practice acts as a way to examine individual 'ways of knowing', identity, and influences upon them. As such, it creates a framework to understand and engage within the context of increased interconnectedness, globalisation, growing diversity (and its impediments), and broad advocacy efforts for both professional practice and higher education.

\section{LIMITATIONS \& FUTURE RESEARCH}

This paper presents a pedagogical tool derived from research learnings. It has not yet been applied in the classroom. Future research, therefore, could explore its applicability in the classroom. Future research could also explore alternative formats for this tool.

\section{CONCLUSION}

This paper outlines a pedagogical tool adapted from a research method in research examining professional identity of public librarians in New Zealand. This tool leverages critical incidents, examined with guided questions, to prompt examination of professional identity. This pedagogical tool is underpinned by reflexive practice, creating a framework to understand and engage within increasingly interconnected contexts. 


\section{REFERENCES}

Angelides, P. (2010). The development of an efficient technique for collecting and analyzing qualitative data: the analysis of critical incidents. International Journal of Qualitative Studies in Education, 14(3), 429-442. https://doi.org/10.1080/09518390110029058

Archer, M. S. (2013). Introduction. In M. S. Archer (Ed.), Conversations about reflexivity (pp. 114). Routledge.

Bak, G. (2002). "The greatest librarians of the world...were not graduates of library school". Libraries \& Culture, 37(4), 363-378. https://doi.org/10.1353/lac.2002.0067

Bennett, G. E. (1988). Librarians in search of science and identity: The elusive profession. The Scarecrow Press.

Drabinski, E. (2016). Valuing professionalism: Discourse as professional practice. Library Trends, 64(3), 604-614.

Flanagan, J. C. (1954). The critical incident technique. Psychological Bulletin, 5, 327-358.

Harris, R. (1992). Librarianship: The erosion of a woman's profession. Ablex Publishing Corporation.

Hicks, D. (2014). The construction of librarians' professional identities: a discourse analysis. Canadian Journal of Information and Library Science, 38(4), 251-270. https://doi.org/10.1353/ils.2014.0017

Hussey, L., \& Campbell-Meier, J. (2016). Developing professional identity in LIS? Education for Information, 32(4), 343-357. https://doi.org/10.3233/EFI-160981

May, T., \& Perry, B. (2012). Reflexive practice. In T. May \& B. Perry (Eds.), Social research and reflexivity: Content consequences and context (pp. 83-100). Sage. https://doi.org/10.4135/9781446250372

McKinney, P., \& Sen, B. A. (2012). Reflection for learning: Understanding the vlaue of reflective writing for informaiton literacy development. Journal of Information Literacy, 6(2), 110-129.

Myers, K. C. (2010). Reflexive practice: Professional thinking for a turbulent world. Palgrave Macmillan.

Pierson, C. M., Goulding, A., \& Campbell-Meier, J. (2019). An integrated understanding of librarian professional identity. Global Knowledge, Memory and Communication, 68(4/5), 413-430. https://doi.org/10.1108/GKMC-01-2019-0008

Pierson, C. M., Goulding, A., \& Campbell-Meier, J. (2020a). Metaphors and critical incidents: Introduction to a methodological approach derived from expressions of librarian professional identity. Information Research, 25(2). http://informationr.net/ir/252/paper859.html

Pierson, C. M., Goulding, A., \& Campbell-Meier, J. (2020b). Professional identity as gateway to critical practices: Identity negotiations of public librarians in New Zealand with implications for LIS education and practice. Journal of the Australian Library and Information Association, 1-16. https://doi.org/10.1080/24750158.2020.1777636

Ryan, M., \& Carmichael, M.-A. (2016). Shaping (reflexive) professional identities across an undergraduate degree programme: A longitudinal case study. Teaching In Higher Education, 21(2), 151-165. https://doi.org/10.1080/13562517.2015.1122586 
Sundin, O., \& Hedman, J. (2009). Professions and occupational identities. In K. E. Fisher, S. Erdelez, \& L. E. F. McKechnie (Eds.), Theories of information behavior (pp. 293-297). Information Today, Inc.

Whyte, W. H. (1956/2002). The Organization Man. University of Pennsylvania Press. 


\section{APPENDIX}

\section{Reflexive practice and professional identity assignment*}

Purpose: The purpose of this assignment is to provide you with an opportunity to explore how critical incidents play a role in shaping professional identities and how this is brought into our professional practice. This assignment situates your individual experience and reflexivity as they relate to your current and/or future professional practice in library and information science (LIS) or galleries, libraries, archives, museums, records (GLAMR) contexts.

You will explore:

- A critical incident(s) in your personal or professional life, related to libraries, archives, knowledge institutions, or the wider GLAMR sector that has/have impacted you and your identity as it relates to such institutions.

- Librarian professional identity. What is it? How is it distinct? How is it formed? What is your sense of your own professional identity?

○ Reading 1: Pierson, C. M., Goulding, A., \& Campbell-Meier, J. (2019). An integrated understanding of librarian professional identity. Global Knowledge, Memory and Communication, 68(4/5), 413-430. https://doi.org/10.1108/GKMC01-2019-0008

- Reflexivity. Reflexivity is often framed around the metaphor of the driver as the knower, the road as the known, and the windshield as the way to know (May \& Perry, 2012). In order to understand reflexive practice and its relationship to identity and professional actions in practice, we must first understand what reflexivity is.

○ Reading 2: Archer, M. S. (2013). Introduction. In M. S. Archer (Ed.), Conversations about reflexivity (pp. 1-14). Routledge.

- Reading 3: Ryan, M., \& Carmichael, M.-A. (2016). Shaping (reflexive) professional identities across an undergraduate degree programme: A longitudinal case study. Teaching In Higher Education, 21(2), 151-165. https://doi.org/10.1080/13562517.2015.1122586

The aim is to consider these elements as they relate to yourself and your position within LIS/GLAMR contexts, to critically engage with and analyse them.

There are 4 submissions making up this assignment:

Reading \& planning segment

Critical incident exploration (Part A: 250-500 words; Part B: 800-1000 words)

Final reflexive essay (1000-1500 words) 


\section{1: Reading \& planning segment}

You will first create a plan for self-directed critical engagement throughout the term. It will be up to you to structure a schedule to engage with, at minimum, readings 1,2 , and 3 and the prompts outlined in the following sections. The due dates you provide will be considered final and subject to relevant university policies. The plan will outline a schedule detailing when each segment will be addressed. If there is a deliverable, the plan will also outline when it is due to the instructor. All assignments are to be completed and turned in no later than the week before the final week of term.

\section{Submission Part 1}

The plan itself may be as detailed or as simple as you like, e.g., annotated bullet points. It must, however, include the action-items listed below and their corresponding due dates.

Readings 1, 2, 3

Critical incident exploration

Part A

Part B

Final reflexive essay

The plan is due:

\section{2: Critical incident exploration}

Critical incidents were introduced as complete occurrences to a person, allowing inference and prediction, whose consequences are unambiguous and thus critically influencing that person in some way (Flanagan, 1954). Modified definitions emphasise 'critical' and incident as based on the meaning and perception given to them by the person who experienced it (Angelides, 2010). Critical incidents have been linked to world- and self-view, indicating an influence on perception as grounded through identity and may also incorporate on-going, situational elements (Pierson et al., 2020).

\section{Submission Part 2A}

You will reflect on a critical incident(s) in your professional life which you consider having impacted your professional identity. If you have not yet been in practice, reflect on a critical incident in your life involving a library/archive/information institution which you consider having impacted you and which you think might be brought into your professional identity.

Consider and address the following questions in 250-500 words collectively:

1. Think of an important event or events that has/have impacted your identity as a librarian/archivist/information professional (or library user/archives user/information professions user). Please describe the event(s).

2. Please elaborate on what specifically made the event(s) impactful to your identity as a librarian/archivist/information professional (or library user/archives user/information professions user). 
The emphasis here is on description of the incident(s) and reflection on what specifically made the event(s) impactful to your identity.

\section{Submission Part 2B}

Now that you have identified your critical incident(s) and what made it so impactful, consider the following reflexive questions in 800-1000 words collectively:

1. Why do you think this was the incident(s) you thought of?

2. How do you think it influenced your professional identity?

3. Why do you think it influenced you the way it did?

These questions prompt reflection of the influences of your critical incident(s) on your professional identity. They prompt further reflection on how these examinations play a role in perceptions of the profession and undertaking library/information professions practice. The emphasis here is less on description and more on analysis of your critical incidents through the questions above.

\section{3: Final reflexive essay}

\section{Submission Part 3}

For the final essay, you will write a short 1000-1500 word piece tying everything in this assignment together. What does it all mean (or what do you think it will mean) for your professional identity in professional practice?

Analyse the incident(s), focusing on what was learned from your answers to the three reflexive questions, and consider any benefits, detriments, and impacts to your professional identity, professional practice, and overall development within an LIS/GLAMR capacity. The emphasis here is less on description - aim not to review what you have done in previous submissions and instead focus more on analysis. It is advised that you connect your analytical writing to research, both in and outside of the course readings.

\section{Important Notes:}

- While it is up to you when and how you address the readings, it is encouraged to take your time to fully engage with and absorb them. Often what is taken to be dense on a first reading comes easier with a second reading.

- Not all incidents will be the same, nor necessarily pleasant ones. You are encouraged to share with the instructor only what you deem relevant and are comfortable with sharing. Only the instructor will see and read what you share.

- The goal here is not psychological assessment, rather to begin engaging with reflexive practice in an individually meaningful way as it applies to LIS/GLAMR contexts. As such, assessment will not be on the content of any incidents, rather the quality of engagement with the prompts and in communication through the written assignments. 
- Finally, something important to consider is the nature of change in the context of all the elements this assignment draws together and what you bring together in your final reflexive essay. Have you noticed a change in your perceptions of the incident(s) from when it initially transpired to now? If so, how? How might any changes be reflected in your answers to the three reflexive questions? Moreover, it is important to consider the nature of change as it relates to the LIS/GLAMR contexts. The information professions are tasked with accommodating great change as we move further into the digital age. Recall that Archer (2013) tells us reflexivity is that "self-referential 'bending back" on our ways of knowing, implying a necessity for persistent reflexivity as contexts, and ourselves within in such contexts, change.

\section{Supplemental Readings}

Angelides, P. (2010). The development of an efficient technique for collecting and analyzing qualitative data: The analysis of critical incidents. International Journal of Qualitative Studies in Education, 14(3), 429-442. https://doi.org/10.1080/09518390110029058

Flanagan, J. C. (1954). The critical incident technique. Psychological Bulletin, 5, 327-358.

Hicks, D. (2014). The construction of librarians' professional identities: A discourse analysis. Canadian Journal of Information and Library Science, 38(4), 251-270. https://doi.org/10.1353/ils.2014.0017

May, T., \& Perry, B. (2012). Reflexive practice. In T. May \& B. Perry (Eds.), Social research and reflexivity: Content consequences and context (pp. 83-100). Sage. https://doi.org/10.4135/9781446250372

McKinney, P., \& Sen, B. A. (2012). Reflection for learning: Understanding the value of reflective writing for information literacy development. Journal of Information Literacy, 6(2), 110-129.

Pierson, C. M., Goulding, A., \& Campbell-Meier, J. (2020a). Metaphors and critical incidents: Introduction to a methodological approach derived from expressions of librarian professional identity. Information Research, 25(2). http://informationr.net/ir/252/paper859.html

Pierson, C. M., Goulding, A., \& Campbell-Meier, J. (2020b). Professional identity as gateway to critical practices: Identity negotiations of public librarians in New Zealand with implications for LIS education and practice. Journal of the Australian Library and Information Association, 1-16. https://doi.org/10.1080/24750158.2020.1777636

Sundin, O., \& Hedman, J. (2009). Professions and occupational identities. In K. E. Fisher, S. Erdelez, \& L. E. F. McKechnie (Eds.), Theories of information behavior (pp. 293-297). Information Today, Inc. 